\title{
O PREFÁCIO DE JOÃO CABRAL DE MELO NETO A EM VA FER JOANBROSSA: TEORIA E PRÁTICA DO REALISMO EM DOIS POETAS DO PÓS- GUERRA
}

Melcion Mateu

Doutorando, New York University

\section{RESUMO}

Em 1951 foi publicado em Barcelona o livro Em va fer Joan Brossa [Fez-me Joan Brossa], do poeta catalão Joan Brossa, com prefácio de João Cabral de Melo Neto. Trata-se de um texto interessante para entender a trajetória de Brossa e a do próprio Cabral e que ajuda a melhor compreender a resposta individual de ambos poetas ao problema da volta ao realismo na geração do imediato pós-guerra. Apresenta-se uma tradução do prefácio de João Cabral de Melo Neto, inédito em português.

\section{PALAVRAS-CHAVE}

João Cabral de Melo Neto; Joan Brossa; poesia; realismo; pós-guerra

THE PREFACE BY JOÃO CABRAL DE MELO NETO TO EM VA FER JOAN BROSSA: THEORY AND PRACTICE OF REALISM IN TWO POETS FROM THE POST-WAR

\section{ABSTRACT}

In 1951, the book Em va fer Joan Brossa [Joan Brossa Made me] was published in Barcelona, with a preface by João Cabral de Melo Neto. It is a useful text to better understand Brossa as well as Cabral; it is a significant text in order to grasp the individual response of these poets to the problem of returning to realism for the early post-war period. A translation of João Cabral de Melo Neto's preface, previously unpublished in Portuguese, is presented here.

\section{KEY-WORDS}

João Cabral de Melo Neto; Joan Brossa; poetry; realism; post-war 


\section{UM TEXTO QUASE INÉDITO}

Em 1951 foi publicado em Barcelona o livro Em va fer Joan Brossa [Fez-me Joan Brossa], escrito, tal como indica o título, pelo poeta catalão Joan Brossa (19191998), com prefácio de João Cabral de Melo Neto (1920-1999). Trata-se de um texto interessante para entender a trajetória de Brossa e a do próprio Cabral, os quais naqueles anos estavam experimentando mudanças importantes na sua voz poética, tanto a respeito da forma como da eleição temática. Também é um texto significativo na medida em que ajuda a melhor compreender a resposta individual de ambos poetas -Cabral e Brossa-- ao problema da volta ao realismo na geração do imediato pós-guerra, mesmo falando de literaturas diferentes --brasileira e catalã-- num contexto posterior a duas guerras consecutivas, a Guerra Civil espanhola (1936-1939) e a II Guerra Mundial (1939-1945).

Não foi, no entanto, um livro muito difundido. Essa primeira edição de $E m$ va fer Joan Brossa teve uma tiragem de 300 exemplares. Naqueles anos começavam a ser publicados legalmente os primeiros livros em catalão pós Guerra Civil, já que a língua fora totalmente proibida no âmbito público durante a década anterior. Outros canais de expressão como a educação, a prensa e os meios audiovisuais tiveram que esperar até o fim da ditadura em 1975. O prefácio de Cabral a Brossa não foi incluído na edição de Poesia Completa e Prosa do poeta brasileiro, publicada pela editora Nova Aguilar, talvez porque o seu original em português estava perdido. A tradução aqui apresentada como apêndice constitui, pois, uma tentativa de reconstrução desse hipotético original em português a partir da versão que Cabral publicou em catalão, e que provavelmente era uma tradução do próprio Brossa, que naqueles anos traduziu também alguns dos seus poemas.

\section{CABRAL EM BARCELONA}

Como é sabido, Cabral se instalou pela primeira vez em Barcelona em 1947 e lá permaneceu como vice-cônsul do Brasil até 1950. Foi a primeira etapa na Espanha de uma carreira diplomática que o levou também a morar, entre outros lugares do país, em Madri (1960-62) e Sevilha (1956 e 1962-1966). Cabral voltou a fazer outra longa estadia em Barcelona em 1967, já como cônsul geral. 
Esta experiência deixa um rastro palpável na obra do poeta pernambucano, cuja relação com a Espanha impregna diferentes níveis da sua criação. Ao mais visível deles, a eleição temática, devemos a metade dos poemas de Paisagens com figuras (19541955), além de livros completos de inspiração espanhola, como Crime na Calle Relator (1985-1987) ou Sevilha Andando (1987-1993), que fecham sua obra poética.

A tradição ibérica, em particular o seu gosto pela poesia medieval castelhana, acabará constituindo a espinha dorsal da poética de Cabral, em especial a partir de $O$ Rio (1953), obra com a qual o poeta inaugura a sua maturidade literária. O próprio poeta admitiu explicitamente essa filiação. ${ }^{1}$ Isto é assim, em parte, porque o poeta reconhece na tradição popular nordestina --a tradição dos repentistas e da literatura de cordel-- os mesmos ritmos da tradição medieval ibérica. Não é um fato casual: com frequência são os pontos mais afastados do centro irradiador aqueles que melhor conservam os rasgos essenciais da cultura arcaica.

Trata-se de uma coincidência dos ritmos mais que da ordenação das rimas. Embora não seja um autor muito interessado na concepção melódica da poesia --ou precisamente por isso--, Cabral é um poeta extremamente cuidadoso com o aspecto rítmico do verso, mesmo para evitar o ritmo regular e musical e aproximar-se a uma dicção mais áspera e prosaica.

\section{UMA QUESTÃO FORMAL}

Em geral, não se tem prestado atenção suficiente à métrica de Cabral. É nos anos imediatamente anteriores e posteriores a sua primeira estadia em Barcelona que o seu verso experimenta as mudanças mais radicais. Do verso livre e da prosa poética que domina os seus primeiros títulos --Pedra de Sono (1941) e Os três Mal-Amados (1943)- passará a uma métrica cada vez mais regular e organizada, próxima a de cultivadores da poesia pura como Paul Valéry ou Jorge Guillén. Não por casualidade Cabral dedica um poema de $O$ Engenheiro (1945) a Valéry e uma epígrafe de Guillén encabeça Psicologia da Composição com a Fábula de Anfion e Antiode (1947).

A partir daqui a métrica de Cabral irá basear-se em modelos formais extraídos da tradição ibérica medieval. O primeiro livro que publica depois desta estadia espanhola,

${ }^{1}$ «É a nossa sorte: nós, artistas de tradição ibérica, podemos recorrer a essa mistura de popular e erudito que vem das fontes.» João Cabral de Melo Neto "João Cabral por Ele Mesmo", Poesia Completa e Prosa (Rio de Janeiro: Nova Aguilar, 2008). pp. xxviii. 
O Rio, leva uma epígrafe bastante significativa neste sentido. É uma cita de uma obra castelhana do século XIII, Los milagros de Nuestra Señora, de Gonzalo de Berceo: "Quiero que compongamos io e tú una prosa". A dicção de Cabral é cada vez mais oral, mais prosaica. Berceo é um dos seus modelos.

Num dos primeiros ensaios sobre Cabral, e o primeiro publicado na Espanha, Ángel Crespo e Pilar Gómez Bedate já assinalaram a relação da métrica do poema de Cabral com a cuaderna vía (estrofes de quatro versos alexandrinos com uma única rima) de autores medievais castelhanos como Berceo ou o Arciprestre de Hita ${ }^{2}$. Escreve Cabral em O Rio:

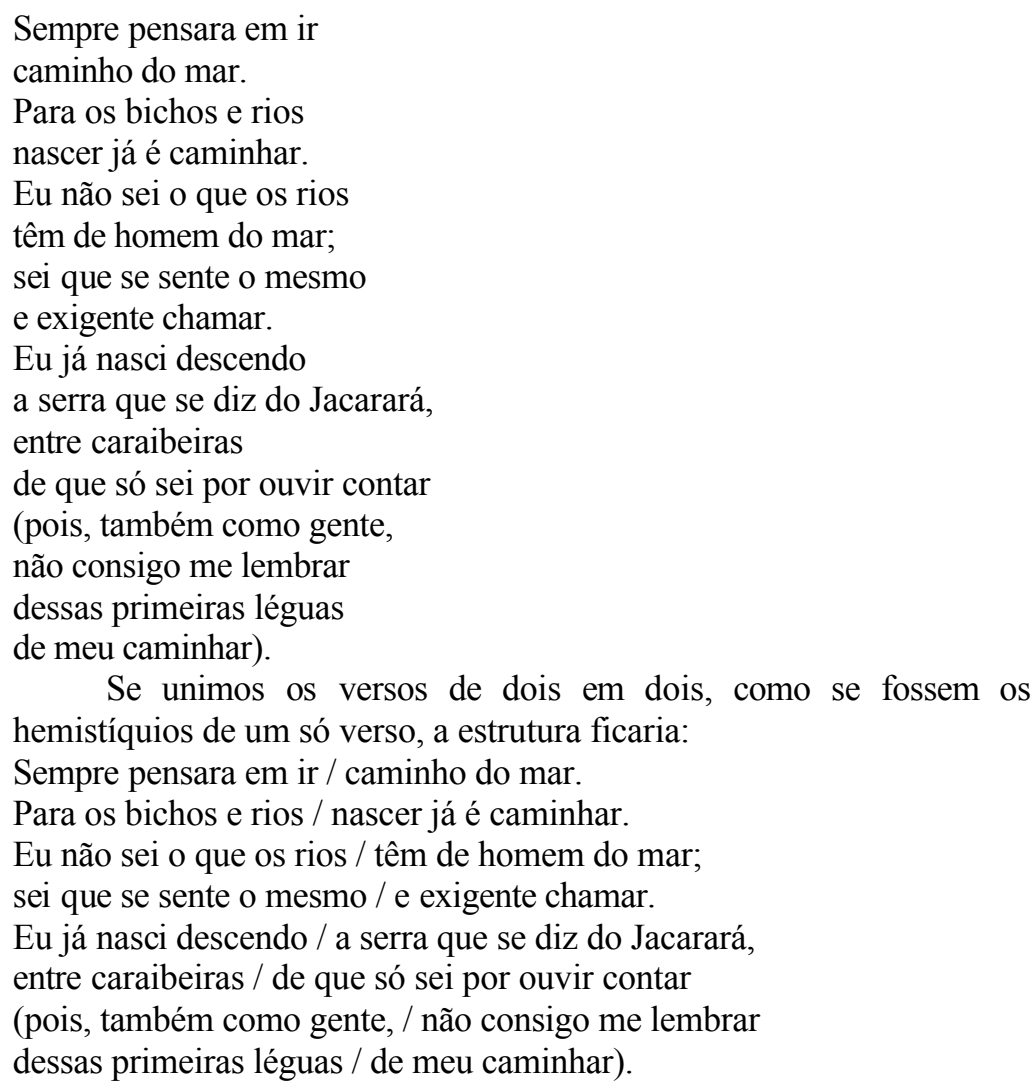

Esta disposição métrica oferece uma clara reminiscência dos poemas medievais castelhanos. Compare-se, por exemplo, com a disposição das rimas nos versos iniciais do mesmo Berceo em Los milagros de Nuestra Señora, obra composta em cuaderna vía:

Amigos e vassallos de Dios omnipotent, si vós me escuchássedes por vuestro consiment,

2 Ángel Crespo e Pilar Gómez Bedate: "Realidad y forma en la poesía de João Cabral de Melo", Revista de Cultura Brasileña. Vol. 8. pp. 5-69. Madri, 1962, pp. 45-46. 
querríavos contar un buen aveniment:

terrédeslo en cabo por bueno verament.

Yo, maestro Gonçalvo de Verceo nomnado, yendo en romería caecí en un prado, verde e bien sencido, de flores bien poblado, logar cobdiciaduero pora omne cansado.

Além dessa similitude, e quanto ao ritmo, a irregularidade métrica de Cabral em $O$ Rio ainda está mais perto da épica medieval castelhana Poema de Mio Cid, precedente imediato do romance espanhol de heptassílabos de rima toante nos pares, mas ainda não perfeitamente regular. Comparem-se os versos de Cabral aos primeiros deste poema épico:

De los sos ojos tan fuerte mientre lorando tornava la cabeça y estava los catando. Vio puertas abiertas e uços sin cañados, alcandaras vazias sin pielles e sin mantos e sin falcones e sin adtores mudados.

Sospiro mio Çid ca mucho avie grandes cuidados.

Ffablo mio Çid bien e tan mesurado: « Grado a ti, señor, padre que estas en alto ¡Esto me an buelto mios enemigos malos!»

É interessante observar que Cabral usou o pseudônimo de Pero Abade -- o copista do único manuscrito conservado do Poema de Mío Cid -- quando apresentou O Rio ao concurso de poesia do IV Centenário de São Paulo, onde obteve o Prêmio José de Anchieta de $1953^{3}$.

A descoberta da modernidade da poesia medieval é algo que Cabral deve aos seus primeiros anos na Espanha e que desenvolverá na sua obra posterior. Em Morte e Vida Severina (1955), por exemplo, segue o modelo dos autos sacramentais medievais. É importante ter em conta que Cabral também traduz, na mesma tradição, Os mistérios da missa do espanhol Calderón de la Barca ${ }^{4}$, e voltará ao modelo da mesma forma dramática no Auto do Frade (1984).

\section{EVOLUÇÃO LITERÁRIA}

Embora frequentemente a crítica atual trate a métrica como uma mera questão ornamental, esta constitui um aspecto fundamental da criação em qualquer poeta que, como Cabral, persiga a união entre forma e conteúdo. Cabral busca uma poesia anti-

\footnotetext{
${ }^{3}$ Benedito Nunes: João Cabral de Melo Neto. Petrópolis: Vozes, 1971, p. 15.

${ }^{4}$ Calderón de la Barca: Os Mistérios da Missa. Tradução de João Cabral de Melo Neto. Rio de Janeiro: Civilização Brasileira, 1963.
} 
lírica, na que a dicção prosaica acompanha umas imagens concretas, definidas, evitando a abstração ou explicitando, "explicando", as metáforas que nela mesma aparecem.

No caso de Cabral, aliás, o movimento de uma forma mais livre em direção ao uma estrutura mais fechada reflete a evolução de uma poesia subjetiva --poesia sobre o poeta, ou sobre a própria poesia-- a outra mais objetiva, sobre a realidade exterior e outros personagens. Não é exatamente assim em Brossa, que evolui de formas fechadas, nas que pratica uma poesia de influência surrealista, a formas mais livres, onde persegue efeitos mais conversacionais. Mas tanto um como o outro poeta --de maneiras diferentes-- reagem em contra de uma poesia "poética" em favor de uma poesia prosaica.

É óbvio que, além das diferenças entre ambos, Cabral se reflete nas suas palavras sobre Brossa. Observe-se como no prefácio Cabral insiste em marcar, na obra de Brossa, o início de uma nova etapa a partir do livro que apresenta. A etapa anterior se identificava com a exploração formal:

Ele já tinha explorado anteriormente todas as variantes do formalismo e todos os cantos dos gabinetes da magia. Desde o balbuciar minuciosamente orquestrado dos Sonets de Caruixa, até a «ópera dos três vinténs» de Dragolí, alternados, sempre, com as prosas e o teatro da alucinação sistemática, com os quais tem buscado o quinto pé do gato e a sétima cara do dado.

Brossa, como o Cabral de Pedra de Sono, também começa a escrever seduzido por uma estética do onírico, de construção irracional. Para sermos justos, Brossa continuará sendo bem mais irracional que Cabral, mas neste caso, e tal como remarca no final do prefácio, o mais importante para Cabral é o interesse psicológico do livro, o jeito como expõe o processo criativo do poeta catalão, a evolução para um novo tipo de poesia. "O nascimento de uma tendência ao qual assistimos neste livro" é para Cabral "frágil como a fonte de onde brota um rio". Cabral se interessa mais pelo posicionamento crítico e criativo de Brossa que pelos resultados imediatos. Um posicionamento crítico não só ante "quase toda a poesia catalã" do seu tempo senão ante sua própria obra prévia a Em va fer Joan Brossa, que coloca o poeta frente à realidade social do seu entorno: "é compreensível que, ao pressentir a falsidade de toda a sua temática anterior, se tenha colocado cara a cara com este vocabulário concreto seu e, para ele, de a realidade de cozinha, de feira e de fundo de oficina, onde a tinha recrutado." João Cabral de Melo Neto defende um novo concepto de realismo: um realismo temático, não formal. Trata-se de uma versão do "realismo social" na que o 
criador tem liberdade para interpretar o real com o seu próprio vocabulário e o seu próprio estilo.

Algumas das idéias expostas por Cabral neste prefácio se refletem noutros textos seus escritos na mesma época. Sob o título "A Geração de 45" o poeta pernambucano publicou no ano seguinte (1952) quatro artigos no Diário Carioca nos quais também insiste na necessidade, num criador, de mostrar passo a passo a evolução de sua estética. Escreve Cabral: "o que já se tem realizado passa desapercebido se o processo não é encarado como um processo em andamento, dinamicamente, ou se se exige desses poetas de 1945 , desde o primeiro momento de luta, uma completa vitória. ${ }^{5}$ Cabral justifica em Brossa suas tentativas anteriores na busca de uma voz e uma poética próprias, do mesmo jeito que vê nos seus companheiros de geração a necessidade de construir o seu projeto literário -- e o seu próprio-- partindo dos avanços conseguidos pelo primeiro Modernismo brasileiro.

Neste sentido, o chamado tríptico do Capibaribe --O Cão sem Plumas, O Rio e Morte e Vida Severina-- ilustra perfeitamente uma evolução gradual da voz poética num movimento que vai do lírico ao dramático. Trata-se de três poemas-livro que partem basicamente do mesmo pretexto poético: o itinerário do rio Capibaribe desde a sua nascente até o mar. Em $O$ Cão sem Plumas (1950) o trajeto do rio é narrado em terceira pessoa, ainda com uma linguagem metafórica; O Rio (1953) passa a converter o Capibaribe em narrador protagonista em primeira pessoa; em Morte e Vida Severina (1955), finalmente, a viagem é protagonizada pela figura do retirante e se apresenta já em forma perfeitamente dramática. Em certa maneira, e considerando sua etapa anterior ao trítico, se poderia comparar este movimento do lírico ao dramático com a hierarquia de gêneros que James Joyce expressa através de Stephen Daedalus em seu Portrait of the Artist as a Young Man (1916): a forma lírica --subjetiva--, a forma épica --híbrida de subjetividade e objetividade-- e a forma superior --já aparentemente objetiva--, a dramática ${ }^{6}$.

"Uma geração" --escreve Cabral na mesma série de artigos-- é definível mais pelos problemas que encontra do que por uma maneira comum de resolver seus

\footnotetext{
5 João Cabral de Melo Neto: "A Geração de 45", em Obra Poética Completa e Prosa (Rio de Janeiro: Editora Nova Aguilar, 2003), p. 727.

${ }^{6}$ Joyce, James. A Portrait of the Artist as a Young Man (Nova Iorque: Penguin, 2003 [1916]), pp. 221-233.
} 
problemas." ${ }^{7}$ Cabral e Brossa partem ao encontro da realidade a partir de tradições distintas e com instrumentos distintos. Mas tanto um como outro incorporaram no seu registro o vocabulário cotidiano das classes populares, e fizeram um uso consciente da sua tradição popular --que no caso de Brossa vai da poesia de Jacint Verdaguer à de Joan Salvat-Papasseit, passando por Joan Maragall.

O interesse de Cabral pela explicitação de uma evolução também impregna outro ensaio importante desta primeira etapa de Cabral na Espanha, a monografia Joan Miró (1950), a primeira sobre o pintor catalão. Segundo confissão própria, o que mais interessa a Cabral não é tanto a pintura de Miró como o que ele interpreta ser a sua teoria pictórica, a maneira como evolui de uma concepção perspectivista da pintura a uma pintura plana, de superfície ${ }^{8}$. Evolução que de alguma maneira reflete o movimento de uma poesia subjetiva a uma objetiva, de uma poesia "profunda" --contra a qual reage-- a um realismo plano, de superfície. Neste sentido é importante ter presente, como declaração de intenções, a "Antiode (contra a poesia dita profunda)", poema que encerra Psicologia da Composição, livro que Cabral publicou na editora e imprensa artesanal que criou em Barcelona, O Livro Inconsútil, em 1947.

As referências de Cabral a "o quinto pé do gato" e à "sétima cara do dado" provavelmente precisem de uma tradução cultural. "Buscarle los tres pies al gato" é, em espanhol, uma expressão usada para designar uma ação ou atitude rebuscada. Com "a sétima cara do dado" Cabral alude à revista Dau al Set (1948-1954), em catalão, literalmente, "dado ao sete", revista fundada pelo próprio Brossa junto com o filósofo e crítico de arte Arnau Puig, os pintores Antoni Tàpies, Modest Cuixart e Joan Ponç e o editor e impressor Joan-Josep Tharrats. Cabral foi muito próximo a este grupo de artistas e intelectuais e colaborou na sua revista, no número de Julho-Agosto de 1949, com os três primeiros poemas de $O$ Engenheiro traduzidos ao catalão por Joan Brossa.

Algumas passagens do prefácio de Cabral a Brossa ficarão refletidos em versos do autor pernambucano. Assim, encontramos um eco de "o quinto pé do gato" e a "sétima cara do dado" no poema "Fábula de Joan Brossa", de Paisagens com Figuras: "Joan Brossa, poeta buscão, / as sete caras do dado, / as cinco patas do cão / antes buscava,

\footnotetext{
${ }^{7}$ Op. cit., p. 724.

8 "Miró sempre me interessou muito pelo que imaginei ser sua teoria da composição. Mas como pintor, me interessa mais um Mondrian, um Malevitch, um Albers, os construtivistas em geral. "João Cabral por Ele Mesmo", em Obra Poética e Prosa, p. xxxiv.
} 
Joan Brossa, / místico da aberração"" . Quando no seu prefácio Cabral fala, a propósito da realidade, que "a maçã existe lá, quando existe, para ser comida ou para ser disputada", é difícil não ter presentes os seguintes versos de $O$ Cão sem Plumas $^{10}$ :

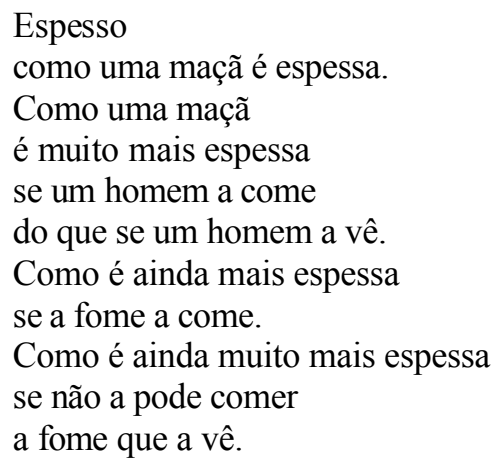

Aqueles primeiros anos na Catalunha foram, pois, especialmente frutíferos para Cabral. Lá o poeta passou de uma poesia "literária", livresca, a uma poesia direitamente relacionada com o seu entorno imediato e comprometido com a situação social em que se produz: com a espessura da fome e as disputas dos homens. Algumas das amizades que cultivou na capital catalã passaram depois a formar matéria poética. Em Paisagens e figuras encontramos, além de Brossa, Miró ("Campo de Tarragona") e o impressor Enric Tormo ("Paisagem tipográfica"). Tormo foi colaborador de outra das iniciativas editoriais de Cabral naqueles anos, a revista $O$ Cavalo de Todas as Cores, da qual apareceu um único número, em Janeiro de 1950. Joan Miró voltará a ser matéria poética em outro poema de Serial (1961), "O Sim contra Sim".

Cabral reencontrará Brossa ao voltar a Barcelona em 1967. Anos depois, em 1994, e junto ao poeta norte-americano John Ashbery, os três poetas participaram no MAM de Rio de Janeiro de um debate organizado por Antonio Cícero e Waly Salomão. Trata-se de três poetas muitos distintos, sem dúvida, que acharam as suas próprias soluções para, essencialmente, os mesmos problemas.

[Tradução ao prefácio João de Cabral de Melo Neto a Em va fer Joan Brossa, de Joan Brossa. Barcelona: Cobalto, 1951.]

Este livro de Joan Brossa reúne os primeiros passos do autor no sentido de realizar uma poesia mais amplamente humana. Mais amplamente humana, ou seja: com o enorme tema dos homens. E não estritamente humana, com os temas de um homem,

\footnotetext{
${ }^{9}$ Ibid., p. 128.

${ }^{10}$ Op. cit, p. 91.
} 
individual, embora sejam os temas da sua sala de jantar, do seu quarto, do seu álcool e de suas máquinas de fugir da realidade.

Esta distinção é muito importante. Talvez o problema essencial da arte atual -a procura de um caminho que o leve a outra coisa, a procura de uma porta de saída--, a superação do seu formalismo se reduz a isto: o reencontro dos homens. O primordial não consiste em abandonar a deformação e a estilização nem, simplesmente, em retornar a uma representação clara do objeto. O feito primordial é saber que objeto se vai pintar, que objeto é digno de ser pintado. É fazer retornar a arte ao tema dos homens.

Há um grande número de artistas irritados com a falsa profundidade do murmuro, contra o mundo falso das super-realidades em que encontraram instalada a poesia, e o qual tinham começado considerar seriamente (é interessante observar a diferença de tom entre um Apollinaire ou um Max Jacob e um jovem poeta de hoje; aquilo que para os primeiros era «humor», para os poetas de hoje torna-se solenidade. Os primeiros «fingiram» crer, os jovens de hoje creem realmente - e daqui o seu tom místico, solene ou desesperado), que hoje lutam por encontrar uma nova forma mais próxima às realidades. Mais -como eles dizem-realista.

A tendência é muito mais generalizada do que parece, e esta obsessão está enraizada até em alguns dos que com mais intensidade -mudada em desesperoseguem se exercitando em todas as tramóias conhecidas para criar esta falsa dimensão arbitrária da realidade.

Contudo, não sempre estes jovens artistas situam a questão sobre os seus pés corretos. O realismo não é uma questão de forma. É essencialmente uma questão de substância, de assunto. Uma maçã em uma bandeja, pintada com o trompe-l'oeil, não será realismo no verdadeiro sentido, senão academicismo. Conseguir, outra vez, a cópia exata de um objeto não nos leva a nenhuma saída definitiva: retornamos ao ponto de partida. Foram as maçãs pintadas -ou seja, a limitação da realidade ao que tem de mais restringido, como esta maçã-, o que levou ao formalismo atual. Da maçã aos simples círculos vermelhos e amarelos de um quadro abstrato, a ponte é mínima. Foi o abandono da dignidade, ou seja, da importância humana (para os homens) dos assuntos, o caminho que a longo prazo fez desembocar os artistas em uma arte que nega radicalmente o assunto. De fato, a importância, para os homens, de um quadro com a bandeja de maçãs e de um quadro com círculos de cor é absolutamente a mesma. Em um certo sentido, quando a pintura desceu até a natureza morta, até o desnudo, à paisagenzinha de tabique, começou se tornar abstrata. 
Perfeitamente consciente de tudo isto, Joan Brossa empreendeu sua reação pelo outro extremo da corda. Ele já tinha explorado anteriormente todas as variantes do formalismo e todos os cantos dos gabinetes da magia. Desde o balbuciar minuciosamente orquestrado dos Sonets de Caruixa, até a «ópera dos três vinténs» de Dragolí, alternados, sempre, com as prosas e o teatro da alucinação sistemática, com os quais tem buscado o quinto pé do gato e a sétima cara do dado. Ele tinha ficado forte nesta retórica, tão forte que, por si mesmo, a tinha aumentado com novos capítulos de sua invenção. Descontente também com toda esta magia, que tinha chegado a julgar «mais real que o real», Brossa, contrariamente a muitos destes jovens que se debatem entre a atual pesquisa da «forma realista», seguiu o caminho oposto: cantar o «real» com a forma de que dispunha.

Ele, apesar de tudo, já parecia conhecer a força deste «real» e adivinhava que acabaria, fatalmente, por fazer explodir sua retórica, eliminando nela tudo aquilo que tem de falso e de artificial e dando um novo sentido - saturado de conteúdo- a aquilo que nela pode constituir enriquecimento para o homem na técnica de se comunicar com outros homens.

Por que Brossa tinha podido chegar a isto (conversas com amigos; simples azares; tédio só) é quase impossível de investigar e definir. Não obstante, se observamos bem aquilo que anteriormente escrevia, esta evolução se nos mostra com uma lógica interna evidentíssima. Talvez porque o seu repertório, profusamente cotidiano e popular, não consistia em uma de suas originalidades? Contrariamente a quase toda a poesia catalã atual, preocupada sempre pelo vocábulo nobre, pouco corrente, erudito e arcaico, era na realidade mais humilde, no léxico de cozinha, de feira, e de fundo de oficina onde Brossa ia buscar o material para elaborar as suas complicadas mitologias. Por isto é compreensível que, ao pressentir a falsidade de toda a sua temática anterior, se tenha colocado cara a cara com este vocabulário concreto seu e, para ele, da realidade de cozinha, de feira e de fundo de oficina, onde a tinha recrutado.

A realidade de cozinha, de feira e de fundo de oficina, porém, não é tão propícia à degustação da natureza morta, ociosa. A maçã existe lá, quando existe, para ser comida ou para ser disputada. A realidade que Brossa descobriu de novo não era o gozo ocioso de um objeto. Aquela realidade estava ritmada para uma luta acendida, onde não era possível abandono nenhum. Nenhum sono, nenhum abandono era possível. Lá o sofrimento não é uma horta para ser cultivada, nem uma coisa para elevar a dignidade, 
senão, por contra, algo que busca ser superado. Essa luta está alerta; é essencialmente viril e, no fundo, já que não se interrompe nem se submete, otimista.

Este livro reúne os primeiros passos que fez Brossa fora da atmosfera impregnada de magia de cartão pedra. A evolução desta nova tendência da sua poesia, o nascimento de uma tendência ao qual assistimos neste livro, frágil como a fonte de onde brota um rio, teria que prosseguir posteriormente: prossegue posteriormente. Eu sinto cada dia mais robusto e forte aquilo que aqui ainda é vacilante e só aponta. Em consequência, o livro ganha um novo interesse psicológico, já que mostra ao descoberto o processo absolutamente exemplar seguido por Joan Brossa e que estou orgulhoso de ter podido acompanhar.

João Cabral de Melo [Neto] 